\title{
High-level fructooligosaccharide production in transgenic tobacco plants
}

\author{
Daisuke Fukutomi ${ }^{1}$, Kyouji Yoshinaka', Sachiko Kawamoto', Takashi Mitsunari ${ }^{1}$, \\ Shinya Kajita ${ }^{2}$, Shinya Kawai ${ }^{1, *}$ \\ ${ }^{1}$ Department of Applied Biological Science, Faculty of Agriculture, Tokyo University of Agriculture and Technology, Fuchu, \\ Tokyo 183-8509, Japan; ${ }^{2}$ Graduate School of Bio-Applications and Systems Engineering, Tokyo University of Agriculture and \\ Technology, Koganei, Tokyo 184-8588, Japan \\ *E-mail: skawai@cc.tuat.ac.jp Tel: +81-42-367-5862 Fax: +81-42-360-6730
}

Received August 1, 2012; accepted October 22, 2012 (Edited by K. Hiratsuka)

\begin{abstract}
FFase) of Aspergillus niger ATCC 20611 can transfer fructosyl residues from one sucrose to another for the synthesis of glucose and fructooligosaccharides composed of 1-kestose $\left(\mathrm{GF}_{2}\right)$, nystose $\left(\mathrm{GF}_{3}\right)$, and $\beta$-fructofuranosylnystose $\left(\mathrm{GF}_{4}\right)$. The FFase gene, under the control of the sporamin gene promoter from sweet potato, was introduced into tobacco plants. Sporamin promoter activity is induced by sugar and exhibits preferential expression in stem and root tissues. Thin-layer and high performance liquid chromatographic analyses showed that soluble extracts from the transgenic plants contained considerable amounts of fructooligosaccharides such as $\mathrm{GF}_{2}$ and $\mathrm{GF}_{3}$. The conversion of sucrose into fructooligosaccharides did not affect plant growth or development. Our results indicate that the transgenic plants could be utilized as bioreactors, and this opens up the possibility for efficient production of fructooligosaccharides in sucroseproducing plants such as sugar beet and sugarcane.
\end{abstract}

Key words: Aspergillus niger, $\beta$-fructofuranosidase, fructooligosaccharides, transgenic plant.

Fructans are synthesized in several plants, and they have important roles as a carbon reserve and resistance to stress. Fructan synthesis is normally initiated by sucrose: sucrose 1-fructosyltransferase, which catalyzes the fructosyl transfer from one sucrose molecule to another, resulting in the trisaccharide, 1-kestose. In 1-kestose, the additional fructose moiety is coupled to the fructose residue of sucrose via a $\beta(1-2)$ linkage. 1-Kestose is used by additional fructosyltransferases to build longer and/ or more complex fructans (Ritsema and Smeekens 2003).

$\beta$-fructofuranosidase (EC 3.2.1.26), FFase, is widely distributed in bacteria, fungi, and plants. FFase has fructosyl transferase (EC 2.4.1.99) activity at high substrate concentrations. Microbial enzymes have been used for fructooligosaccharide production from sucrose. Fructooligosaccharides have a natural sweetness, color, and scent similar to sucrose, and they possess beneficial qualities such as non-cariogenicity and relief of digestion problems.

One of the FFases, FopA, produced by Aspergillus niger ATCC 20611, has unique characteristics and exhibits higher transferase activity compared to hydroxylase as well as strong fructosyl transfer activity at the $\beta(1-2)$ linkage at high sucrose concentrations (Hidaka et al.
1988). The purified FFase catalyzes the synthesis of fructooligosaccharides, with inulin-type structure, in the following manner:

Sucrose $(\mathrm{GF})+$ sucrose $(\mathrm{GF}) \rightarrow 1$-kestose $\left(\mathrm{GF}_{2}\right)+$ glucose, $\mathrm{GF}_{2}+$ sucrose $\rightarrow$ nystose $\left(\mathrm{GF}_{3}\right)+$ glucose, $\mathrm{GF}_{3}+$ sucrose $\rightarrow$ $\beta$-fructofuranosylnystose $\left(\mathrm{GF}_{4}\right)+$ glucose. Yanai et al. (2001) successfully cloned the FopA gene from A. niger ATCC 20611 and produced a recombinant protein in yeast.

It has been reported that the sugars that are industrially produced by using microorganisms can be made directly in plants. For example, palatinose, a structural isomer of sucrose, was produced in transgenic tobacco plants and potatoes by introducing the sucrose isomerase gene from Erwinia rhapontici (Börnke et al. 2002b). From an industrial point of view, if fructooligosaccharides could be transformed from high concentrations of sucrose in transgenic plants, it opens up the possibility of a novel production system for the functional sugars. Therefore, we generated transgenic tobacco plants producing fructooligosaccharides by inducing the expression of an FFase gene, fopA, under the control of sweet potato sporamin promoters. Because the expression of the sporamin gene is induced by

Abbreviations: FFase, $\beta$-fructofuranosidase; $\mathrm{GF}_{2}, 1$-kestose; $\mathrm{GF}_{3}$, nystose; $\mathrm{GF}_{4}, \beta$-fructofuranosylnystose; CaMV35SP, cauliflower mosaic virus $35 \mathrm{~S}$ promoter; GUS, $\beta$-glucuronidase.

This article can be found at http://www.jspcmb.jp/

Published online March 19, 2013 


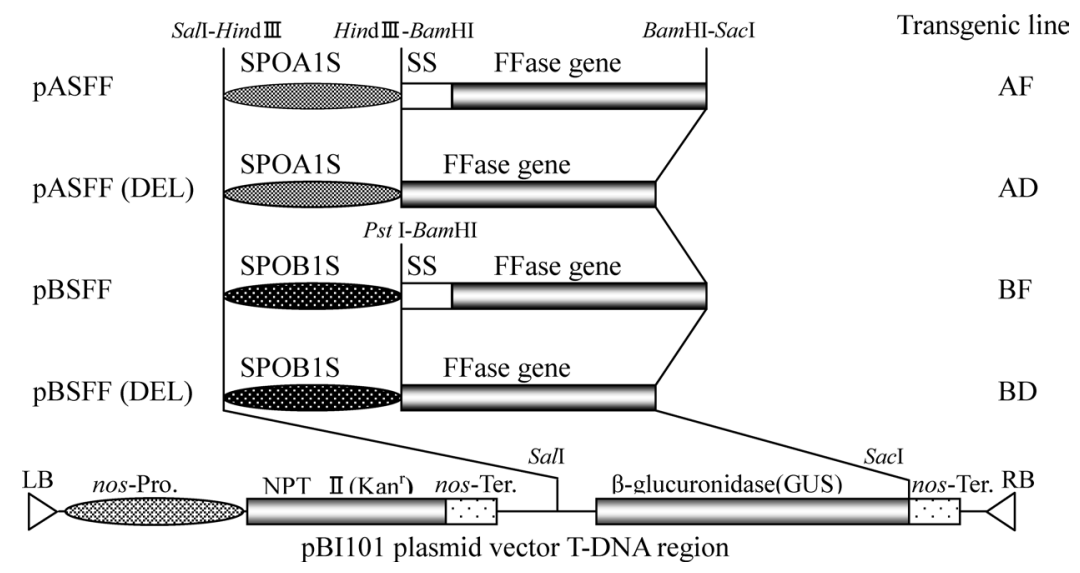

Figure 1. Illustration of the promoter and FFase gene constructed in the binary vector pBI101. SPOA1S represents the $5^{\prime}$ upstream region of gSPO-A1. SPOB1S represents the $5^{\prime}$ upstream region of $g S P O-B 1$. pASFF and pBSFF contain the fopA signal sequence (SS). The GUS (uidA) sequence of pBI101 was replaced with each of the SalI-SacI fragments of the FFase expression cassette in pBluescript KS(-). Tobacco plants transformed with pASFF, pASFF (DEL), pBSFF, and pBSFF (DEL) are named AF, AD, BF, and BD transgenic lines, respectively.

sucrose (Morinaka et al. 2005), it is expected that the transgenes with the sporamin promoter will be strongly expressed in response to endogenous sucrose in the plants.

\section{Construction of expression vectors}

An FFase gene, fopA (accession number AB046383), from Aspergillus niger ATCC 20611 was used to construct the expression vectors (Yanai et al. 2001). The gene consists of an open reading frame of $1962 \mathrm{bp}$ that encodes 654 amino acid residues, including an $\mathrm{N}$-terminal secretion signal sequence of 19 amino acid residues. In this study, we prepared expression cassettes with and without the nucleotide sequence for the signal sequence. The coding regions were fused to the $3^{\prime}$-portions of sporamin promoters, which are $5^{\prime}$ upstream regions of two sporamin genes, gSPO-A1 (accession number X13509) and gSPO-B1 (accession number X13510). Sporamin genes are composed of a closely related multigene family, which can be classified into two major subfamilies, sporamin A and sporamin B. To isolate two sporamin promoter regions, DNA fragments were PCR amplified from total DNA purified from the sweet potato (Ipomoea batatas (L.) Lam. cv. Kokei 14). The following gene-specific primers were used for the reaction: $5^{\prime}$-TAAGCTTAAT TTA CTA ATT TGG GGT TTT AC- $3^{\prime}$ and $5^{\prime}$-AAAGCTTAGA GGT AAT GAT GTTTAA TTT GT- $3^{\prime}$ for the upstream region of $g S P O-A 1$, and $5^{\prime}$-TAAGCTTTAG GTT CAC TCA CCT TAA GTT TC-3' and $5^{\prime}$-ACTGCAGGCA ATT TAT AGA GGA CAT GAG -3' for the upstream region of $g S P O-B 1$. The underlined sequences are additional restriction enzyme recognition sites for HindIII or PstI. PCR products of the $5^{\prime}$ upstream region of the $g S P O-A 1$ (SPOA1S) and the $g S P O-B 1$ (SPOB1S) were cloned into the pT7blue vector. To fuse the promoter with fopA and create the FFase expression cassette, HindIII fragments containing SPOA1S were subcloned into the HindIII site located upstream of fopA or fopA (DEL), which lacks the signal sequence, and inserted into the BamHI site of pBluescript KS(-). The HindIII-Pst I fragments containing SPOB1S were also inserted into the HindIIIPstI sites located upstream of the fopA or the fopA (DEL) in the plasmids. Each of the SalI-SacI fragments containing the FFase expression cassettes was isolated and replaced with the SalI-SacI fragment containing uidA for GUS in pBI101 binary plasmid vectors for plant transformation (Figure 1). The expression vectors with $f_{\circ p A}$, with and without the signal sequence, under SPOA1S or SPOB1S were designated as pASFF, pASFF (DEL), pBSFF, and pBSFF (DEL), respectively.

\section{Genetic transformation of tobacco plants}

A binary vector containing each expression cassette was introduced into Agrobacterium tumefaciens LBA4404 by electroporation. Nicotiana tabacum cv. Samsun NN was transformed with the resultant $A$. tumefaciens by using the leaf-disk method. The transgenic plants were grown at $25^{\circ} \mathrm{C}$ under sterilized conditions in $16 \mathrm{~h}$ light $/ 8 \mathrm{~h}$ dark cycle.

The transgenic plants transformed with pASFF, pASFF (DEL), pBSFF, and pBSFF (DEL) were named AF, AD, $\mathrm{BF}$, and $\mathrm{BD}$ lines, respectively. Over 10 independent primary transformants were obtained for each construct and successful transformation was confirmed by PCR using fopA specific primers (data not shown). The growth and developmental characteristics of the transgenic lines were indistinguishable from other lines and the wild-type plants (date not shown). Among the resultant transgenic plants, one or two transgenic plants for each line (AF1, $\mathrm{AD} 4, \mathrm{AD} 12, \mathrm{BF} 1, \mathrm{BF} 2, \mathrm{BD} 10$, and $\mathrm{BD} 12)$ were selected as representatives for further studies. 


\section{Soluble carbohydrate extraction from tobacco plants}

Stem and root tissues (1.5-g strips) were taken from mature plants that grew to a height of approximately $30 \mathrm{~cm}$ in pots with soil. The samples were immediately quenched in liquid nitrogen, and they were powderized using mortars and pestles. Soluble carbohydrate was extracted from the resultant samples in $1.5 \mathrm{ml}$ of distilled water at $80^{\circ} \mathrm{C}$ for $1.5 \mathrm{~h}$. After the incubation, the samples were centrifuged at $2000 \mathrm{rpm}$ for $5 \mathrm{~min}$, the supernatants were recovered, and then centrifuged again at $10000 \mathrm{rpm}$ for $5 \mathrm{~min}$. The final supernatants were collected as the soluble carbohydrate solution.

\section{Thin-Layer Chromatography (TLC) analyses of the extracted soluble carbohydrates}

To qualitatively analyze the composition of soluble carbohydrates, the extracted soluble carbohydrates were separated by TLC (MERCK HPTLC-Platten glass sheets $10 \times 10$ silica gel 60$)$. A small amount of the extract $(20 \mu \mathrm{L})$ was spotted on a layer. Layers were developed twice using chloroform:acetone: water $(6: 7: 1, \mathrm{v} / \mathrm{v})$ in a vertical trough glass chamber with mobile phase vapor saturation. For visualization of the soluble carbohydrates, the layers were sprayed with detection regent $(2 \mathrm{~g}$ diphenylamine, $2 \mathrm{~mL}$ aniline, $100 \mathrm{~mL}$ acetone, $15 \mathrm{~mL}$ phosphoric acid) and incubated for $15 \mathrm{~min}$ at $110^{\circ} \mathrm{C}$. A fructooligosaccharide standard was purchased from Wako Pure Chemical Industries, Ltd. (Osaka, Japan), containing 45-50\% 1-kestose, 45-50\% nystose, and 7-8\% 1 - $\beta$-fructofranosylnystose.

Separated sugars on the plate were visualized with different colors by using a detection reagent. Three types of fructooligosaccharides, $\mathrm{GF}_{2}, \mathrm{GF}_{3}$, and $\mathrm{GF}_{4}$, were detected in brown and their mobility was lower compared to that of the other sugars. In addition to typical plant sugars such as fructose, glucose, and sucrose, extracts from $\mathrm{AF}, \mathrm{AD}, \mathrm{BF}$, and $\mathrm{BD}$ lines contained additional sugars with lower mobilities on the chromatogram. These sugars could be assigned as fructooligosaccharides by comparing them with authentic compounds. Fructooligosaccharides were detected in both stem and root extracts from these transgenic lines. Additionally, the patterns of sugar composition were similar in both tissues.

\section{High performance liquid chromatography (HPLC) analyses}

Tissue extracts were filtered through filter membranes. The samples were analyzed by HPLC equipped with a LichroCART column $(250 \mathrm{~mm} \times 4.0 \mathrm{~mm}$; Merck KGaA, Darmstadt, Germany). The mobile phase was composed of $71 \%$ acetonitrile and pumped at a flow rate of $1 \mathrm{~mL} /$ min. Detection was performed on a refractive index detector.

Two fructooligosaccharides, $\mathrm{GF}_{2}$ and $\mathrm{GF}_{3}$, from the root tissues of transgenic and wild type plants were also quantitatively monitored by HPLC. The results of these analyses confirmed that the transgenic lines produced fructooligosaccharides at detectable levels. Table 1 indicates the Mol-to-Mol ratios of each sugar to sucrose in root tissue extracts. A high level of $\mathrm{GF}_{3}$ and $\mathrm{GF}_{4}$ was observed in the $\mathrm{BF}$ lines, which were rarely seen in the $\mathrm{AF}, \mathrm{AD}$, and $\mathrm{BD}$ lines. In the Mol ratio, fructooligosaccharide content in the BF1 line accounted approximately $40 \%$ of the total soluble carbohydrates detected in the analyses. As indicated in the TLC analyses and Table 1, the expression cassette with the gSPO-B1 promoter and the FFase gene with the signal sequence seems more efficient for fructooligosaccharide conversion when compared to the other vectors.

Previously, it has been reported that expression of plant fructosyltransferase transgenes in variety of transgenic plants induces the synthesis of fructans and fructooligosaccharides or increases their contents (Hellwege et al. 1997; Hisano et al. 2004; Jenkins et al. 2002; Kawakami et al. 2008; Ritsema and Smeekens, 2003; Sévenier et al. 1998; Stoop et al. 2007; Weyens et al. 2004). Successful accumulation of bacterial fructan (levan; $\beta$-2,6-linked fructan) has been also achieved by the introduction of bacterial levan sucrase into transgenic plants (reviewed by Cairns 2003). In this

Table 1. HPLC analyses of root extracts of transgenic tobacco plants.

\begin{tabular}{|c|c|c|c|c|c|}
\hline & \multicolumn{5}{|c|}{ Mol ratio of carbohydrates to sucrose } \\
\hline & Fru/Suc & Glc/Suc & $\mathrm{Suc} / \mathrm{Suc}$ & $\mathrm{GF}_{2} / \mathrm{Suc}$ & $\mathrm{GF}_{3} / \mathrm{Suc}$ \\
\hline WT & 0.35 & 0.59 & 1 & n.d. & n.d. \\
\hline AF1 & 0.19 & 0.37 & 1 & 0.14 & n.d. \\
\hline AD4 & 0.41 & 0.46 & 1 & n.d. & n.d. \\
\hline AD12 & 0.41 & 0.56 & 1 & n.d. & n.d. \\
\hline BF2 & 0.32 & 0.43 & 1 & 0.34 & 0.24 \\
\hline BD10 & 0.27 & 0.49 & 1 & 0.1 & n.d. \\
\hline BD12 & 0.29 & 0.53 & 1 & 0.1 & n.d. \\
\hline
\end{tabular}

Soluble carbohydrate content was determined by HPLC. Mol ratio of fructooligosaccharides to sucrose is shown. Fru, fructose; Glc, glucose; Suc, sucrose; $\mathrm{GF}_{2}$, 1-kestose; $\mathrm{GF}_{3}$, nystose; n.d., not detected. 
study, we also tried to produce fructooligosaccharides in transgenic tobacco plants. To the best of our knowledge, this is the first report of a transgenic plant that accumulates the inulin-type fructooligosaccharides after the expression of a fungal FFase gene under the control of the sporamin promoter.

Sucrose is transported through the sieve elements and parts of the phloem by a partitioning process. Transgenic tobacco plants containing the sucrose isomerase gene under the control of the CaMV $35 \mathrm{~S}$ promoter, which converted sucrose to platinose, show severe phenotypic alternations (Börnke et al. 2002a). Gene expression in specific tissues that contain sucrose reduced stress in plants. However, our transgenic plants displayed no phenotypic alterations at the maturing stage. Thus, the sporamin promoter characteristics, including sucroseinducible and phloem-preferential properties, are thought to be suitable for efficient fructooligosaccharide production from sucrose. In fact, large amounts of $\mathrm{GF}_{2}$ and $\mathrm{GF}_{3}$ and a trace amount of $\mathrm{GF}_{4}$ can be detected in the transgenic lines with the FFase gene under the sporamin promoter (Fig. 2). As expected, the sporamin promoter may be induced, at least in part, by sucrose that was loaded from source organs to the phloem. The resultant sucrose may be partially converted to fructooligosaccharides.

As shown in Figure 2 and Table 1, fructooligosaccharide accumulation by the FFase with the signal peptide was more efficient compared to that without the signal peptide. It is possible that the signal peptide has critical roles in regulating accurate conformation and/or stable activity of the FFase protein. In the transgenic plants, the $\mathrm{N}$-terminal signal peptide derived from $A$. niger may target the recombinant FFase to apoplastic regions. Furthermore, changes in sucrose and hexose contents and their compositions occurred by apoplasmic expression of yeast-derived invertase in transgenic potato tubers and transgenic tobacco (Sonnewald et al. 1997; Hajirezaei et al. 2000; Canam et al. 2006). Thus, accumulation of sugar-metabolizing enzymes in the apoplastic region may be beneficial for altering sugar compositions.

The purpose of this study was to accumulate fructooligosaccharides in the model plant to search for the possibility of bioreactors in sucrose-producing plants. However, we have two questions regarding fructooligosaccharide accumulation at the molecular level. First, oligosaccharide translocation in plants has not been elucidated adequately. Two types of unloading have been proposed: symplastic type and apoplastic type (Giaquinta et al. 1983). Because the unloading mechanism is complicated, it is necessary to investigate whether fructooligosaccharides in the phloem are transported to sink organs. Second, sucrose is stored in the vacuole in sugar beet or sugarcane. Therefore, it is
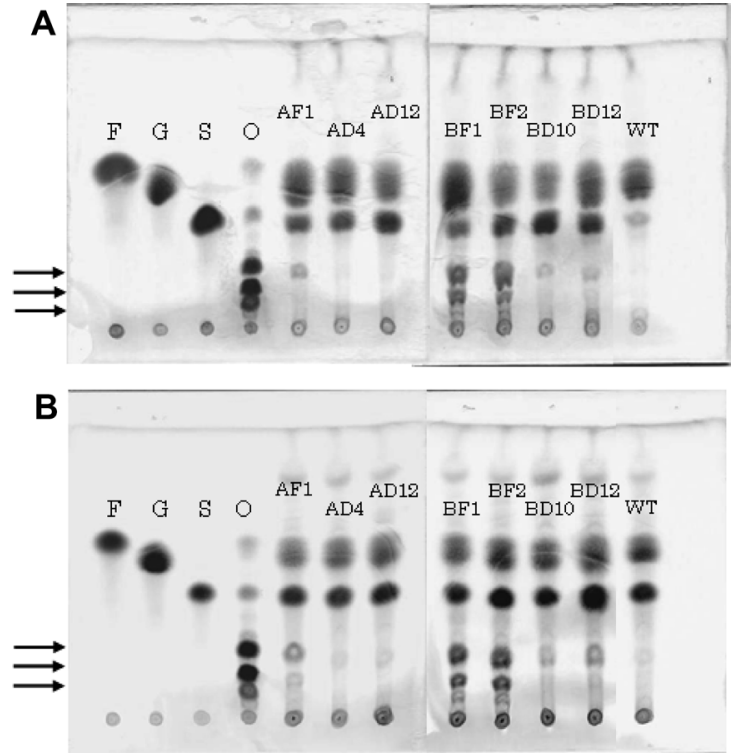

Figure 2. TLC analyses of extracts from the lower stems (A) and roots (B) of transgenic tobacco plants. F, fructose standard; G, glucose standard; S, sucrose standard; O, fructooligosaccharides standard. The arrows indicate the position of fructooligosaccharides, $\mathrm{GF}_{2}$ (above), $\mathrm{GF}_{3}$ (middle), and $\mathrm{GF}_{4}$ (below).

also essential to examine whether the constructs used in this study can be applied to sugar beet or sugarcane. Though some problems remain, we have confirmed that the sugar-related enzyme of $A$. niger functioned effectively in plants, and the influence of this newly produced sugar was not pronounced in plants. Thus, these data lead to applied research of plant molecular biology, including that of transgenic crop plants.

Fructooligosaccharide production in the storage tissues of transgenic plants is less efficient than industrial production by the enzyme method. From a physiological point of view, glucose made as a by-product is converted to sucrose again, which is the carbon source, and then sucrose is assumed to again be the substrate of the enzyme. Therefore, the reaction rate does not decrease because substrate concentration is maintained. Our results show that transgenic tobacco plants are capable of producing fructooligosaccharides. However, when the purity and the unit price are considered, industrial production might be more cost-effective. Further studies should be undertaken to characterize the biochemical pathways discussed herein and to improve in planta fructooligosaccharide production.

\section{References}

Börnke F, Hajirezaei M, Heineke D, Melzer M, Herbers K, Sonnewald U (2002a) High-level production of the noncariogenic sucrose isomer palatinose in transgenic tobacco plants strongly impairs development. Planta 214: 356-364

Börnke F, Hajirezaei M, Sonnewald U (2002b) Potato tubers as bioreactors for palatinose production. J Biotechnol 96: 119-124 
Cairns AJ (2003) Fructan biosynthesis in transgenic plants. J Exp Bot 54: 549-567

Canam T, Park JY, Yu KY, Campbell MM, Ellis DD, Mansfield SD (2006) Varied growth, biomass and cellulose content in tobacco expressing yeast-derived invertases. Planta 224: 1315-1327

Giaquinta RT, Lin W, Sadler NL, Franceschi VR (1983) Pathway of phloem unloading of sucrose in corn roots. Plant Physiol 72: 362-367

Hajirezaei MR, Takahata Y, Trethewey RN, Willmitzer L, Sonnewald U (2000) Impact of elevated cytosolic and apoplastic invertase activity on carbon metabolism during potato tuber development. J Exp Bot 51 (Spec No): 439-445

Hellwege EM, Gritscher D, Willmitzer L, Heyer AG (1997) Transgenic potato tubers accumulate high levels of 1-kestose and nystose: functional identification of a sucrose sucrose 1-fructosyltransferase of artichoke (Cynara scolymus) blossom discs. Plant J 12: 1057-1065

Hidaka H, Hirayama M, Sumi N (1988) A Frucroligosaccharideproducing enzyme from Aspergillus niger ATCC-20611. Agric Biol Chem 52: 1181-1187

Hisano H, Kanazawa A, Kawakami A, Yoshida M, Shimamoto Y, Yamada T (2004) Transgenic perennial ryegrass plants expressing wheat fructosyltransferase genes accumulate increased amounts of fructan and acquire increased tolerance on a cellular level to freezing. Plant Sci 167: 861-868

Jenkins CLD, Snow AJ, Simpson RJ, Higgins TJ, Jacques NA, Pritchard J, Gibson J, Larkin PJ (2002) Fructan formation in transgenic white clover expressing a fructosyltransferase from Streptococcus salivarius. Funct Plant Biol 29: 1287-1298

Kawakami A, Sato Y, Yoshida M (2008) Genetic engineering of rice capable of synthesizing fructans and enhancing chilling tolerance. J Exp Bot 59: 793-802

Ritsema T, Smeekens SCM (2003) Engineering fructan metabolism in plants. J Plant Physiol 160: 811-820

Sévenier R, Hall RD, van der Meer IM, Hakkert HJC, van Tunen AJ, Koops AJ (1998) High level fructan accumulation in a transgenic sugar beet. Nat Biotechnol 16: 843-846

Sonnewald U, Hajirezaei MR, Kossmann J, Heyer A, Trethewey RN, Willmitzer L (1997) Increased potato tuber size resulting from apoplastic expression of a yeast invertase. Nat Biotechnol 15: 794-797

Stoop JM, Van Arkel J, Hakkert JC, Tyree C, Caimi PG, Koops AJ (2007) Developmental modulation of inulin accumulation in storage organs of transgenic maize and transgenic potato. Plant Sci 173: 172-181

Weyens G, Ritsema T, Van Dun K, Meyer D, Lommel M, Lathouwers J, Rosquin I, Denys P, Tossens A, Nijs M, Turk S, Gerrits N, Bink S, Walraven B, Lefèbvre M, Smeekens S (2004) Production of tailor-made fructans in sugar beet by expression of onion fructosyltransferase genes. Plant Biotechnol J 2: 321-327

Yanai K, Nakane A, Kawate A, Hirayama M (2001) Molecular cloning and characterization of the fructooligosaccharideproducing $\beta$-fructofuranosidase gene from Aspergillus niger ATCC 20611. Biosci Biotechnol Biochem 65: 766-773 